\title{
HARLEQUIN FOETUS
}

\author{
BY \\ I. KESSEL and F. C. FRIEDLANDER \\ From the Transvaal Memorial Hospital for Children and the Department of Pediatrics \\ of the University of the Witwatersrand
}

(RECEIVED FOR PUBLICATION SEPTEMBER 22, 1955)

Harlequin foetus, the most severe form of congenital ichthyosis, is a rare condition and infants suffering from the abnormality are pitiable objects. The first description of the condition is probably that of the Rev. Oliver Hart of Charleston, U.S.A., who, in 1750 , recorded in his diary the description of a newborn infant with this severe type of skin disease. His description, which bears repetition, fits our case perfectly and is an excellent piece of clinical reporting.

'The skin was dry and hard and seemed to be cracked in many places, somewhat resembling the scales of a fish. The mouth was large and round and wide open. It has no external nose but two holes where the nose should have been. The eyes appeared to be lumps of coagulated blood, turned out, about the bigness of a plum, ghastly to behold. It had no external ears but holes where the ears should be. The hands and feet appeared to be swoln, were crumpt up and felt hard. The back part of the head was much open. It made a strange kind of noise, very low, which I cannot describe. It lived about eight and forty hours and was alive when I saw it.'

Most descriptions of the condition are similar to this one, quoted by Lattuada and Parker (1951) and written over 200 years ago.

\section{Case Report}

A white male infant, aged 4 hours, was admitted to the Transvaal Memorial Hospital for Children on October 5, 1954.

No history was obtained on admission, as the infant was sent in by ambulance unaccompanied. Subsequent questioning of the parents revealed that a previous infant had died at birth with a similar condition. There were several siblings who were all quite well and the parents were both fit and healthy. The pregnancy was uneventful.

The infant presented a striking abnormality of the skin, which was hard, horny and of a yellowish-white colour where the horny layer was thickest. In the body folds the skin was fissured and these cracks were an eighth to a quarter of an inch deep in some places. The under- lying skin appeared red and not grossly abnormal in the cracks; there was some blood-stained ooze in these areas. The skin of the abdomen was severely affected, while the skin of the back and thorax was less thickened.

The skin of the face had the same appearance as that on the rest of the body. Ectropion of the upper and lower lids was so severe that there was complete eversion of both lids. The mouth was shaped like an $\mathrm{O}$ due to the severe hyperkeratosis. The ears were deformed.

The infant lay with the arms flexed at the shoulders and elbows and the hands flexed on the forearms. The thighs were flexed on the trunk and the knees and ankles were also flexed. This extreme flexion was due to the very thickened, inelastic skin. Bands of hyperkeratotic epidermis were present on several fingers and toes, causing deformities.

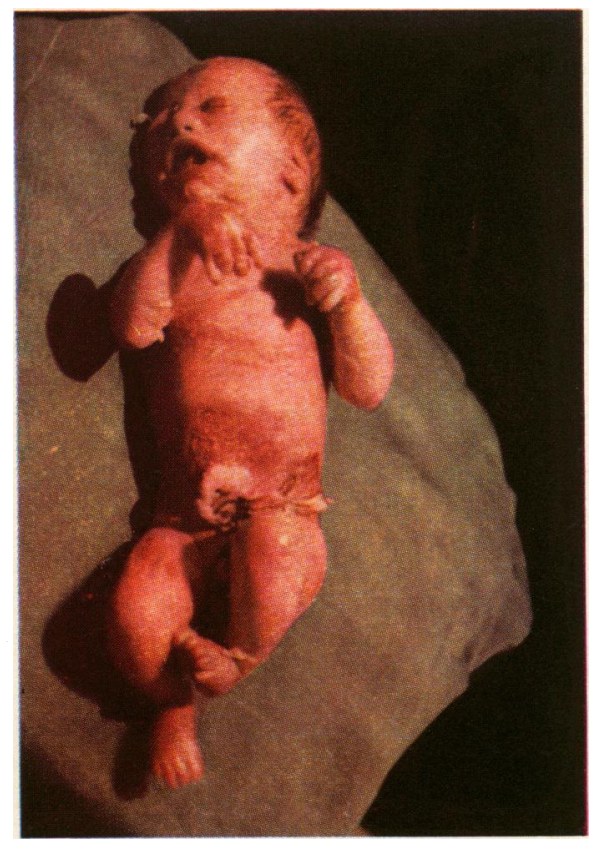

FIG. 1.-The general appearance of the infant. 
Further examination revealed no other abnormality in any of the systems. The temperature was subnormal ( $96^{\circ}$ F.).

The patient's progress was marked by extension of the fissuring and some loss of large flakes of hyparkeratotic skin, leaving a somewhat reddish, granular skin underneath. This more normal-looking skin persisted until death.

The infant was given a diluted sweetened condensed milk feed and managed to take this from a bottle. He passed meconium on the day after admission, i.e., at about 20 hours of life, and thereafter passed one to three stools per day. The temperature remained subnormal for 72 hours and fluctuated thereafter between $98^{\circ} \mathrm{F}$. and $98 \cdot 6^{\circ} \mathrm{F}$. Urine was passed, but it was not possible to estimate the amount.

As a previous case seen in this hospital had shown lower nephron nephrosis (acute tubular necrosis) at necropsy (Kessel and Javett, 1955) a blood urea estimation was done on the second day, revealing a level of $93 \mathrm{mg} . \%$. On the fourth day the level of the blood urea had risen to $129 \mathrm{mg}$. \%. The Ide blood test for syphilis was negative.

The further course was downhill and the infant died on the fifth day.

A skin biopsy taken from an area of extreme hyperkeratosis on the abdomen before death was reported on by Dr. H. Lurie, of the South African Institute for Medical Research, as follows: Section of this specimen of skin from the left flank showed solid hyperkeratosis. The granular layer was present and the rete Malpighii was acanthotic. The pegs tended to be flattened. There were a few small foci of intracellular oedema. In the dermis there were numerous follicles and sweat glands. The amount of elastic tissue was definitely diminished.

Necropsy was performed by one of us (F.F.) and apart from the gross external appearance noted above there was nothing remarkable noted macroscopically. The thyroid gland appeared normal in size, but unfortunately was not sent for histological study. Two sections of skin were sent, one from an area in the neck where the thickened epidermis had peeled off, the other from the wrist.

A histological study of relevant sections was reported on by Dr. H. Lurie as follows:

A section of the specimens from the kidneys showed a lower nephron nephrosis, of the specimen of skin from the wrist solid hyperkeratosis (Fig. 2). The stratum granulosum was present. The rete Malpighii showed papillary acanthosis. The papillae appeared to be compressed. In the dermis there were numerous sweat glands and a few follicles. The amount of elastic tissue was markedly diminished. Section of the specimen of skin from the neck showed slight hyperkeratosis. The stratum granulosum was increased in thickness and the cells appeared to be keratinized. The rete Malpighii showed acanthosis and dyskeratosis resembling that of a keratoma. In addition there was a small suprabasal cleft. In the dermis there were a few sweat glands and follicles. There was a slight diminution in the amount of elastic tissue.

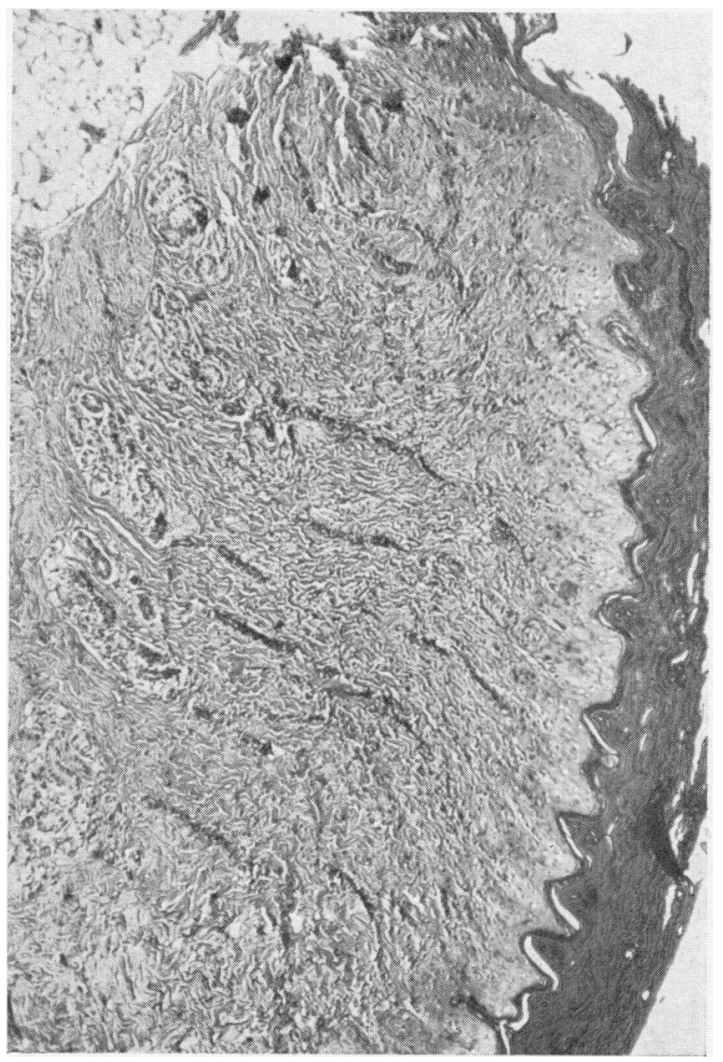

FIG. 2.-Section of skin from the wrist.

\section{Discussion}

This infant is the second case of harlequin foetus seen in this hospital within six months, in itself a remarkable occurrence. The first case has been reported elsewhere (Kessel and Javett, 1955).

The name 'harlequin foetus' is applied to these infants either because of the clown-like appearance of the face with the round $\mathrm{O}$ of the mouth or, more probably, because of the deep fissuring of the skin, often with diamond-shaped or triangular plaques of hyperkeratotic epidermis which give the impression of a harlequin's costume. The fissures are found most commonly in areas of movement and are, therefore, found predominantly in the body folds, i.e., the groins, axillae, neck, and over joints. Movement of other parts of the body will cause them to appear in other sites. The hyperkeratosis and inelasticity of the skin cause deformities of the limbs and the infants lie with their arms flexed at the shoulders and elbows and the legs flexed at the hip and knee. The wrists, fingers, ankles and toes may also be held in the flexed position, as, indeed, they 
were in our case. The eyelids are everted and a severe degree of ectropion exists. Hair is not present or is very sparse. Hyperkeratotic bands may encircle fingers and toes and impair their blood supply.

The skin may peel leaving a reddish, fairly normallooking skin underneath, but this layer also hardens and loses its suppleness after a short time, with the eventual reiteration of the original appearance. Our case did not live long enough for the whole cycle to occur, but areas of desquamation did appear with skin underneath which did not appear grossly abnormal. In this respect the harlequin foetus differs from those cases of 'collodion skin' described by Finlay and Bound (1952) and others, in which the desquamation of abnormal skin leaves normal epidermis underneath. The abnormal skin of the harlequin foetus has been compared by various authors to a variety of objects, viz., baked apple or sucking pig, boiled potatoes, the bark of a tree, pieces of parchment, a loosely-built wall, morocco leather, a coat of mail, armadillo or tortoise, elephant skin, rhinoceros skin, crocodile leather or lizard skin (MacLaverty and Kidney, 1952).

The pathological lesion is hyperkeratosis of the epidermis with no, or a grossly deficient, stratum granulosum. The prickle layer is thin. The cutis is normal except for dilated sweat ducts and acini. This is probably due to the fact that the ducts are occluded by hyperkeratosis.

The familial aspect of the disease is apparent in this case as the infant under discussion is not the first in the family suffering from the disease. This has been noted before by Thomson and Wakeley (1921), d'Oelsnitz, Vichier, Chabert and Vigneron (1952) and Sutton and Sutton (1939).

It has been noted at necropsy that the thyroid gland may be rudimentary (Thomson and Wakeley, 1921) and, therefore, treatment with thyroid has been recommended. One feels that this is a somewhat forlorn hope as no treatment appears to be of any avail (Sutton and Sutton, 1939). No connection with congenital syphilis has been noted and in our case the blood Ide test was negative. Treatment, therefore, should be symptomatic, i.e., aimed at amelioration of the skin lesion, prevention of hyperpyrexia and prevention of infection in the deep cracks in the skin. It must be remembered that feeding may be difficult due to the deformity of the mouth.

The prognosis is hopeless as all patients die very young. MacLaverty and Kidney (1952) state that their case and one other in the literature, both of which lived to 6 weeks, are the longest-lived of reported cases.

The cause of death is not generally noted. Lattuada and Parker (1951) state that death is usually due to hyperpyrexia, infection or metabolic disturbance. In view of the necropsy findings in their case and in the case of Kessel and Javett we did blood urea estimations on our patient on the second and the fourth days of life. These estimations disclosed a severe and progressive degree of renal impairment which was borne out by the microscopical findings at necropsy. The cause of the lower nephron nephrosis is difficult to assess. It is possible that there may be tubular damage from hyperpyrexia, although the rectal temperature in our case was never elevated, or that the splinting of the chest by the thick skin may lead to insufficient oxygenation of the blood and kidney damage subsequent to the hypoxia (Kessel and Pepler, 1955).

\section{Summary}

A case of harlequin foetus is reported and a brief review of the literature given. It is noted that this case and another reported from this hospital showed lower nephron nephrosis at necropsy.

We would like to thank Dr. K. Mills, Medical Superintendent of the Johannesburg Group of Hospitals, Dr. A. E. Strawbaun, former senior paediatrician to the Transvaal Memorial Hospital for Children, for permission to record this case, Dr. Sher of Johannesburg, for the colour photographs, and Dr. H. Lurie for his histological reports.

\section{REFERENCES}

Finlay, H. V. L. and Bound, J. P. (1952). Archives of Disease in Childhood, 27, 438.

Kessel, I. and Pepler, W. J. (1955). J. Obstet. Gynaec. Brit. Emp., $62,98$.

- and Javett, S. N. (1955). In the press.

Lattuada, H. P. and Parker, M. S. (1951). Amer. J. Surg., 82, 236.

MacLaverty, M. and Kidney, W. (1952). J. Irish med. Ass., 31, 295. d'Oelsnitz, M. A., Deschamps, Vichier, H., Chabert, P. and Vigneron (1952). Pediatrie, 7, 1123.

Sutton, R. L. and Sutton, R. L. (Jr.) (1939). Diseases of the Skin, 10 th ed., pp. 567-74. St. Louis.

Thomson, M. S. and Wakeley, C. P. G. (1921). J. Obstet. Gynaec. Brit. Emp., 28, 190. 